\title{
Coenzyme Q10 Supplementation Decreases Oxidative Stress and Improves Physical Performance in Young Swimmers: A Pilot Study
}

\author{
Donrawee Leelarungrayub $^{*}, 1$, Narongrat Sawattikanon ${ }^{2}$, Jakkrit Klaphajone ${ }^{3}$, Prapas Pothongsunan ${ }^{1}$ \\ and Richard J. Bloomer ${ }^{4}$
}

\author{
${ }^{I}$ Oxidative Stress and Exercise Biochemical Laboratory, Department of Physical Therapy, Faculty of Associated \\ Medical Sciences, Chiang Mai University, 50200, Chiang Mai, Thailand \\ ${ }^{2}$ Sports Sciences, Graduate School, Chiang Mai University, 50200, Chiang Mai, Thailand \\ ${ }^{3}$ Department of Rehabilitation Medicine, Faculty of Medicine, Chiang Mai University, 50200, Chiang Mai, Thailand \\ ${ }^{4}$ Cardiorespiratory/Metabolic Laboratory, Department of Health and Sport Sciences, University of Memphis, USA
}

\begin{abstract}
Background: The purpose of this study was to evaluate the effects of short term (12 day) Coenzyme Q10 (CoQ10) supplementation on blood oxidative stress biomarkers and physical performance in young swimmers.

Methods: Sixteen young swimmers ( 7 males and 9 females, aged $15.13 \pm 0.96$ years) who were involved in a sport hero project at Chiang Mai province participated as subjects during this 22 day study. Regular training for swimmers was carried out for the first 9 days. Supplementation with 300mg CoQ10 (Soft gel; Swanson Ultra, USA) was then administered daily for 12 days. Blood samples were collected in EDTA-anticoagulant tubes before (days 1 and 9 of the control period) and after the 12 day supplementation period (day 22). Plasma was separated and used for the determination of malondialdehyde (MDA), nitric oxide (NOx), protein hydroperoxide ( $\mathrm{PrOOH})$, total antioxidant capacity (TAC), and CoQ10; whereas reduced glutathione (GSH) was measured in erythrocytes. Exhaustive exercise time was evaluated before (days 1 and 9) and after-supplementation (day 22) on a mechanical treadmill using a modified Bruce protocol. Swimming speeds for both 100 and 800 meters were also recorded. Repeated measurement and Bonferroni correction were used for statistical analysis $(p=0.05)$.

Results: Over the course of the 9 day control period before supplementation, all parameters (MDA, NOx, PrOOH, CoQ10, GSH, TAC, treadmill exhaustion time, and swimming time for either 100 or 800 meters) did not differ ( $>00.05$ ). After CoQ10 supplementation, the levels of plasma MDA, NOx, and PrOOH were significantly decreased when compared to the pre-supplement period $(\mathrm{p}<0.05)$. Moreover, plasma CoQ10 $(2.34 \pm 0.78 \mu \mathrm{g} / \mathrm{ml} v s 1.10 \pm 0.38 \mu \mathrm{g} / \mathrm{ml})$ and erythrocyte GSH $(14.51 \pm 1.99 v s 8.90 \pm 1.84 \mu \mathrm{mol} / \mathrm{g} \mathrm{Hb})$ significantly increased $(\mathrm{p}<0.05)$. Maximal treadmill time was increased significantly $(22.92 \pm 4.89$ mins $)$ when compared to pre-CoQ10 supplementation $(\mathrm{p}<0.05)$, whereas, the swimming time improved significantly for 100 meters when compared to pre-supplementation $(p<0.05)$, with no difference in swim time recorded for 800 meters $(\mathrm{p}>0.05)$.
\end{abstract}

Conclusion: Twelve days of CoQ10 supplementation reduces oxidative stress, improves running time until exhaustion, as well as short distance swim sprint time, within a sample of young swimmers.

\section{INTRODUCTION}

Professional swimming is a competitive and challenging sport in many countries, including Thailand. The hero sport program in Chiang Mai province was designed to develop young swimmers into professional or national caliber athletes. There are three main swimming styles; free style, butterfly, and breast stroke. Energy production is produced via two metabolic pathways during swimming; anaerobic metabolism by the phosphocreatine (PC) and glycolysis pathways, and aerobic metabolism by the electron transport system [1]. Some evidence has shown that prolonged swimming in child or adolescent athletes leads towards an imbalance in redox status by increased oxidative stress and

*Address correspondence to this author at the Oxidative Stress and Exercise Biochemical Laboratory, Department of Physical Therapy, Faculty of Associated Medical Sciences, Chiang Mai University, 50200, Chiang Mai, Thailand; E-mail: nuttakan@chiangmai.ac.th decreased antioxidant capacity [2]. Regular bouts of swimming have been shown to increase lipid peroxidation and decrease antioxidant glutathione (GSH) in various organs such as the liver, kidney and brain of rat models [3, 4] Thus, supplementation with antioxidant nutrients may provide protection to young swimmers who may be prone to exercise-induced oxidative stress.

To this end, a previous study in humans recommended increased macronutrient intake in the form of bananas or carbohydrate gels, in combination with isotonic sports drinks, which are preferred by marathon swimmers [5]. On the other hand, isolated micronutrient supplementation, although widespread in the sporting world for purposes of improved performance and enhanced antioxidant capacity, has not received widespread acceptance. However, we have observed recently that many adolescent swimmers have increased interest in using micronutrient supplements including multi-vitamins and minerals, as well as various 
nutrients proposed to be ergogenic aids, in an attempt to improve swimming performance and to minimize oxidative stress. Coenzyme Q10 (CoQ10) protects against free radical invasion [6], and has been used as a preventative and treatment aid for many organ disorders [7]. Moreover, CoQ10 has been reported to enhance athletic performance in sports such as skiing [8]. More recent work indicates an improvement in muscle CoQ10 level, oxygen consumption, and treadmill time to exhaustion in adults following only 14 days of supplementation at $200 \mathrm{mg}$ daily [9]. However, to our knowledge, no study has investigated the antioxidant and performance effects of CoQ10 supplementation in a sample of young swimmers. Hence, this was the purpose of the present study. Although this study included a small sample of young swimmers in a local province in Thailand, our findings provide interesting pilot data that may be considered for developing future studies with a greater sample size in which results may be generalized to a larger population of athletes.

\section{MATERIALS AND METHODOLOGY}

\section{Subjects and Physical Characteristics}

This research program was approved by the Human Ethics Committee at the Faculty of Associated Medical Sciences, Chiang Mai University, Thailand. All 16 young swimmers included were involved in a sport hero program in Chiang Mai province. A baseline pulmonary function test was conducted following the Standardization of lung function testing (ATS/ERS task force) [10] with a Spirometer HI-101 (Chest MI, Inc, Tokyo, Japan). Each swimmer made at least three, and not more than eight, repeated attempts and the highest value for each parameter was recorded, as recommended by the American Thoracic Society (1995) [11]. Completed blood count (CBC) was analyzed by the central laboratory at the Faculty of Associated Medical Sciences, Chiang Mai University, Thailand.

\section{Experimental Design}

The study timeline consisted of a 9 day control period, followed by a 12 day period of CoQ10 supplementation (Soft gel; Swanson, USA) at a dosage of $300 \mathrm{mg}$ daily. Blood collection and physical performance tests were performed in the morning between 9.00-10.00 a.m before breakfast on the first and the ninth day of the control period, in addition to the day following the final day of CoQ10 supplementation. Therefore, a total of three data collection days were included within this 22 day design (day 1, day 9, day 22). Regular food intake was permitted throughout the study period and subjects were instructed to maintain their usual diet and activity profile. Health symptoms or side effects such as vomiting, headaches and skin rash were inquired upon daily by telephone. Ten milliliters of whole blood were collected in EDTA-anticoagulant tubes. Plasma was separated by centrifugation at 3,000 rpm for 5 minutes used for the measurement of the oxidative stress markers; nitric oxide (NOx), malondialdehyde (MDA), protein hydroperoxide (PrOOH), total antioxidant capacity (TAC), and CoQ10. Erythrocyte was assayed for reduced glutathione (GSH). Methods for these assays are described below.

\section{Nitric Oxide Assay}

Plasma nitric oxide was evaluated by griess reagent following Promega's Instructions for use of the Griess reagent system [12]. First, $200 \mu 1$ of plasma were mixed with $500 \mu \mathrm{l}$ of $0.1 \%$ of $N$-1-napthylethylenediamine dihydrochloride (NED) in water and left in the dark for $5 \mathrm{~min}$, then $500 \mu \mathrm{l}$ of $1 \%$ sulfanilamide were added to $5 \%$ phosphoric acid and kept in the dark again for $5 \mathrm{~min}$. Then a slightly pink color was produced with an absorbance reading at $520 \mathrm{~nm}$. Nitrite in plasma was calculated by comparing with the absorbance of standard sodium nitrite $\left(\mathrm{NaNO}_{3}\right)(0-40 \mu \mathrm{mol} / \mathrm{L})$.

\section{Malondialdehyde Assay}

The protocol was modified from the original report of Chirico (1994) [13], and slightly modified by following Leelarungrayub's protocol [14]. $250 \mu \mathrm{l}$ of plasma was mixed with $750 \mu \mathrm{l}$ of ortho-phosphoric acid $(2.5 \%, v: v)$ and vortexed. Then, $500 \mu \mathrm{l}$ of TBA $(0.2 \mathrm{~mol} / \mathrm{L})$ in Tris solution $(0.14 \mathrm{~mol} / \mathrm{L})$ was added. After incubation in a water bath $\left(90^{\circ} \mathrm{C}\right)$ for $30 \mathrm{~min}$, all samples were cooled and centrifuged at $10,000 \mathrm{rpm}$ for $3 \mathrm{~min}$. A clear pink color of supernatant was read with a spectrophotometer at $532 \mathrm{~nm}$. The yield of MDA in the sample was calculated by comparing with the absorbance of standard Tetramethoxypropane (TMP) (Sigma) (0-50 $\mu \mathrm{mol} / \mathrm{L})$.

\section{Protein Hydroperoxide Assay}

The protocol was modified from that of Gay (2003) [15]. Plasma protein at $200 \mu \mathrm{l}$ was precipitated with $0.5 \mathrm{~mol} / \mathrm{L}$ perchloric acid (PCA) and resolved with $700 \mu$ l of guanidine hydrochloride (GuHCL) (6 mol/L). Then, $40 \mu \mathrm{l}$ of $0.2 \mathrm{~mol} / \mathrm{L}$ of perchloric acid, $25 \mu \mathrm{l}$ of xylenol orange $(5 \mathrm{mmol} / \mathrm{L})$, and $20 \mu \mathrm{l}$ of ferrous solution $(5 \mathrm{mmol} / \mathrm{L})$ were added. The whole mixture was left in the dark for $30 \mathrm{~min}$ before being centrifuged at 10,000 rpm for $3 \mathrm{~min}$. The yellow supernatant was read for absorbance at $560 \mathrm{~nm}$. The level of protein hydroperoxide was calculated by comparing with the standard tert-butyl hydroperoxide $(0-10 \mu \mathrm{mol} / \mathrm{L})$.

\section{Glutathione Assay}

Reduced glutathione in erythrocyte was determined with a modified protocol of Leelarungrayub (2003) [16]. Whole blood at $400 \mu \mathrm{l}$ was dissolved in $1.0 \mathrm{ml}$ of deionized water and $3.0 \mathrm{ml}$ of precipitating solution that contained $0.2 \mathrm{~mol} / \mathrm{L}$ glacial meta-phosphoric acid, $0.68 \mathrm{mmol} / \mathrm{L} \mathrm{EDTA-Na}$, and $0.5 \mathrm{~mol} / \mathrm{L} \mathrm{NaCl}$, respectively. Clear supernatant at $200 \mu \mathrm{l}$ was mixed with $500 \mu \mathrm{l}$ of $0.1 \mathrm{~mol} / \mathrm{L}$ phosphate buffer $(\mathrm{pH}$ $8.0)$ and $500 \mu \mathrm{l}$ of DTNB solution (4\%) in $0.2 \mathrm{mmol} / \mathrm{L}$ of sodium citrate after centrifugation at $10,000 \mathrm{rpm}$ for $3 \mathrm{~min}$. After leaving for $5 \mathrm{~min}$ in room temperature, an absorbance mixture of yellow color was read at $412 \mathrm{~nm}$. The reduced GSH was calculated by comparing with the absorbance of standard reduced GSH (Sigma) (0-50 mmol/L). Reduced $\mathrm{GSH}$ was presented in a unit of $\mu \mathrm{mol}$ in one gram of $\mathrm{Hb}$ ( $\mu \mathrm{mol} / \mathrm{g} \mathrm{Hb})$.

\section{Total Antioxidant Capacity (TAC) Assay}

Total antioxidant capacity of fresh plasma was assayed with ABTs cation radical decolorization [17]. Stock ABTs cation radical was produced by mixing ABTS $(14 \mathrm{mmol} / \mathrm{L})$ and potassium persulfate $(14 \mathrm{mmol} / \mathrm{L})$ together and leaving in the dark overnight. Working ABTs cation radical was diluted from stock ABTs with deinoized water, until absorbance at $734 \mathrm{~nm}$ was shown at $0.7 \pm 0.2$ before adding plasma. The $10 \mu \mathrm{l}$ of plasma was added to $990 \mu \mathrm{l}$ of working 
solution ABTs cation radical in a plastic cuvette (size 1.5 $\mathrm{ml}$ ), and gently shaken 9 times before adding again in the spectrophotometer. Decreased absorbance was recorded continuously every $1 \mathrm{~min}$ for 3 minutes, and finally calculated to $\Delta \mathrm{A} / \mathrm{min}$. Total antioxidant capacity (TAC) of plasma was calculated by comparing with the $\Delta \mathrm{A} / \mathrm{min}$ of standard Trolox (0-10 $\mathrm{mmol} / \mathrm{L})$.

\section{CoQ10 Assay}

The protocol for determining CoQ10 in plasma was modified from the Graves et al. protocol [18] by using the reverse-phase-HPLC C-18 (Spherisorb ODS-2, $5 \mu \mathrm{m}$, $4.6 \times 250 \mathrm{~mm}$ column; Water company). A mixture of $200 \mu 1$ of plasma and $20 \mu \mathrm{l}$ of internal standard CoQ9 $(0.5 \mu \mathrm{g} / \mathrm{ml})$ was denatured by adding $3.0 \mathrm{ml}$ of fresh ethanol $/ \mathrm{n}$-hexane $(2: 5, v: v)$. After vortexing for $2 \mathrm{~min}$ and centrifuging at 300 $\mathrm{g}$ for $10 \mathrm{~min}$ at $4^{\circ} \mathrm{C}, 1.30 \mathrm{ml}$ of organic $\mathrm{n}$-hexane was separated for evaporation under nitrogen gas and reconstituted with $100 \mu \mathrm{l}$ of ethanol/n-hexane $(6: 4, v: v)$. Only $20 \mu \mathrm{l}$ was injected into a $20 \mu \mathrm{l}$ sample loop. Interestingly, CoQ10 and internal CoQ9 control peaks were eluted, and showed a mobile phase (methanol hexane $(6: 4$, $v: v)$ with a running flow at $1.0 \mathrm{ml} / \mathrm{min}$ by using a Conta Meric LDL analyzer with UV detector $(\lambda=275 \mathrm{~nm})$. The CoQ10 concentration in plasma was calculated by comparing with the high peak of standard CoQ10 (0-20 $\mu \mathrm{g} / \mathrm{ml})$.

\section{Physical Performance Tests}

All swimmers were evaluated for maximal time to exhaustion on a mechanical treadmill using a modified Bruce protocol [ACSM's guideline, 2000] [19]. Familiarization to the treadmill protocol was provided. Swimming speeds for both 100 and 800 meters were also recorded, with each subject performing three trials of each, with the best times recorded and used in data analysis.

\section{Statistical Analysis}

All blood and performance parameters across the three measurement times (days 1, 9, and 22) were tested with repeated measurement in the general linear model, using a Post-Hoc (Bonferroni) test. Significance was set at $p \leq 0.05$.

\section{RESULTS}

Characteristics of all 16 young swimmers ( 7 males and 9 females, mean age 15.13 \pm 0.96 ) were healthy; body mass index (BMI) was $20.74 \pm 1.88 \mathrm{~kg} / \mathrm{m}^{2}$ and the pulmonary function tests (PFT) were normal $(\mathrm{FVC}=110.84 \pm 16.05 \%$, FEV1 $=93.33 \pm 10.07 \%$ of predicted) (Table 1). Results for the lung function investigation [20] and CBC analysis were within normal range.

\section{Oxidative Stress and Antioxidant Biomarkers}

Before the supplementation period (days 1 and 9) values for MDA, NOx, and PrOOH, as well as GSH, TAC, and CoQ10 were not statistically different $(\mathrm{p}>0.05)$ (Table 2 and Figs. 1-6). Following the 12 day CoQ10 supplementation period, the results showed significantly $(\mathrm{p}<0.05)$ lower oxidative stress in regards to MDA $(2.77 \pm 0.52$ to $1.94 \pm 0.79$ $\mu \mathrm{mol} / \mathrm{L})($ Fig. 1), NOx $(37.86 \pm 4.61$ to $30.39 \pm 8.65 \mu \mathrm{mol} / \mathrm{L})$
(Fig. 2), and $\mathrm{PrOOH}(2.42 \pm 0.50$ to $1.62 \pm 0.47 \mu \mathrm{mol} / \mathrm{L})(\mathrm{Fig}$. 3), whereas, antioxidant conditions improved in GSH $(8.9 \pm 1.84$ to $14.51 \pm 1.99(\mu \mathrm{mol} / \mathrm{g} \mathrm{Hb})$ (Fig. 4), TAC $(0.93 \pm 0.11$ to $1.02 \pm 0.11 \mathrm{mmol}$ Trolox/L) (Fig. 5), and CoQ10 (1.10 \pm 0.38 to $2.34 \pm 0.78 \mu \mathrm{g} / \mathrm{ml})$ (Fig. 6).

Table 1. Characteristics and Pulmonary Function Test of All 16 Young Swimmers on Day 1 of the Control Period

\begin{tabular}{|c|c|c|}
\hline Variables (Normal Values) & Mean (SD) & Min-Max \\
\hline Age $(y r)($ male $=7$, female $=9)$ & $15.13(0.96)$ & $14-17$ \\
\hline $\begin{array}{l}\text { BMI }\left(\mathrm{kg} / \mathrm{m}^{2}\right) \\
19.1-25.8 \mathrm{Kg} / \mathrm{m}^{2} \text { in women* } \\
20.7-26.4 \mathrm{~kg} / \mathrm{m}^{2} \text { in men* }\end{array}$ & $20.74(1.88)$ & $17.32-24.32$ \\
\hline \multicolumn{3}{|c|}{ Pulmonary function test (AST guideline) } \\
\hline FVC (\%) & $110.84(16.05)$ & $82.60-148.30$ \\
\hline FEV1 (\%) & $93.33(10.07)$ & $75.40-113.00$ \\
\hline MMF (\%) & $122.36(29.72)$ & $94.00-179.20$ \\
\hline $\mathrm{FEF}_{75}(\%)$ & $115.10(29.77)$ & $81.40-173.20$ \\
\hline
\end{tabular}

Abbreviations: $\mathrm{BMI}=$ body mass index, $\mathrm{FVC}=$ forced vital capacity, $\mathrm{FEV} 1$ = forced expiratory volume at 1 second, $\mathrm{MMF}=$ maximal flow rate, FEF75 = forced expiratory flow at $75 \%$. * BMI reference from the NHANES II survey (USA 1976-1980) [National Heart, lung and blood Institute, 1998].

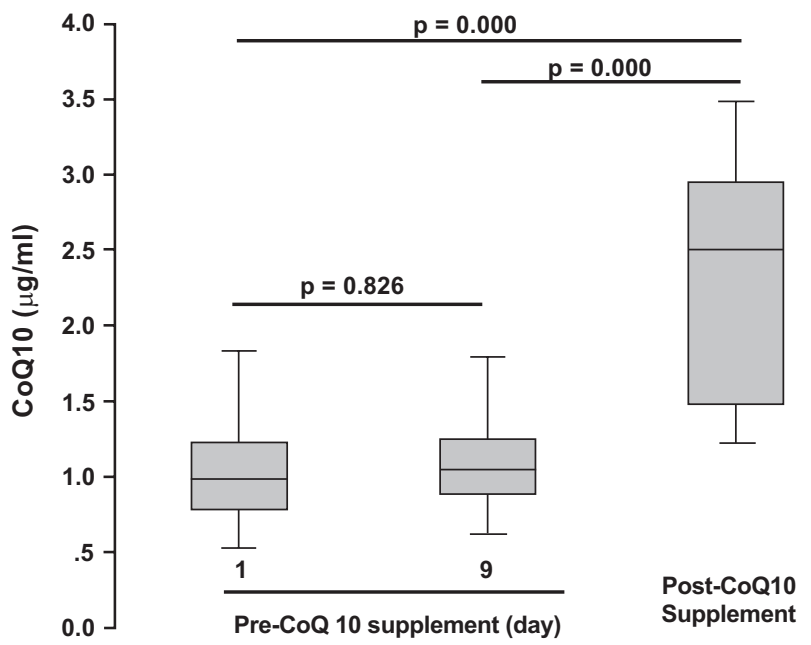

Fig. (1). Plasma MDA (mmol/L) at days 1 and 9 of pre-CoQ10 supplementation and post-CoQ10 supplementation, at $300 \mathrm{mg}$ daily for 12 days in the 16 young swimmers. MDA was assayed with a TBARs reagent. Each box plot represents the mean and standard deviation (SD). Repeated measurement in the general linear model and Bonferroni (Post Hoc) was used for statistical analysis with a $\mathrm{p} \leq 0.05$ level.

\section{Physical Performance}

After CoQ10 supplementation, running time until exhaustion was significantly increased (22.92 $\pm 4.89 \mathrm{~min})$ when compared to pre-supplementation $(20.14 \pm 4.47 \mathrm{~min})$ $(p<0.05)$. Swimming time for the 100 meter sprint was significant improved when compared to pre-supplementation $(p<0.05)$. No effect was noted for the 800 meter sprint swim $(\mathrm{p}>0.05)$. Data are shown in Table 3. 


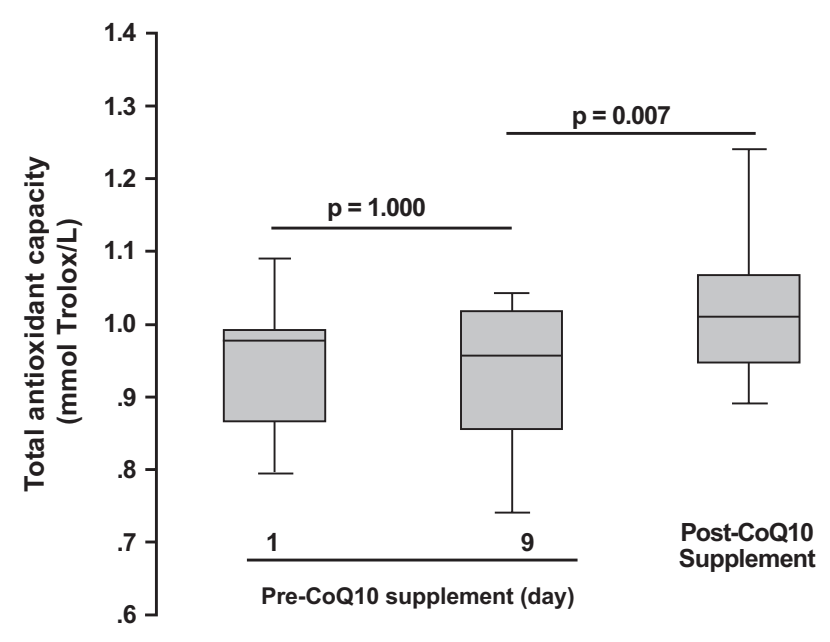

Fig. (2). Plasma NOx ( $\mu \mathrm{mol} / \mathrm{L})$ at days 1 and 9 of pre-CoQ10 supplementation and post-CoQ10 supplementation, at $300 \mathrm{mg}$ daily for 12 days in the 16 young swimmers. NOx was assayed with a griess reagent. Each box plot represents the mean and standard deviation (SD). Repeated measurement in the general linear model and Bonferroni (Post Hoc) was used for statistical analysis with a $\mathrm{p} \leq 0.05$ level.

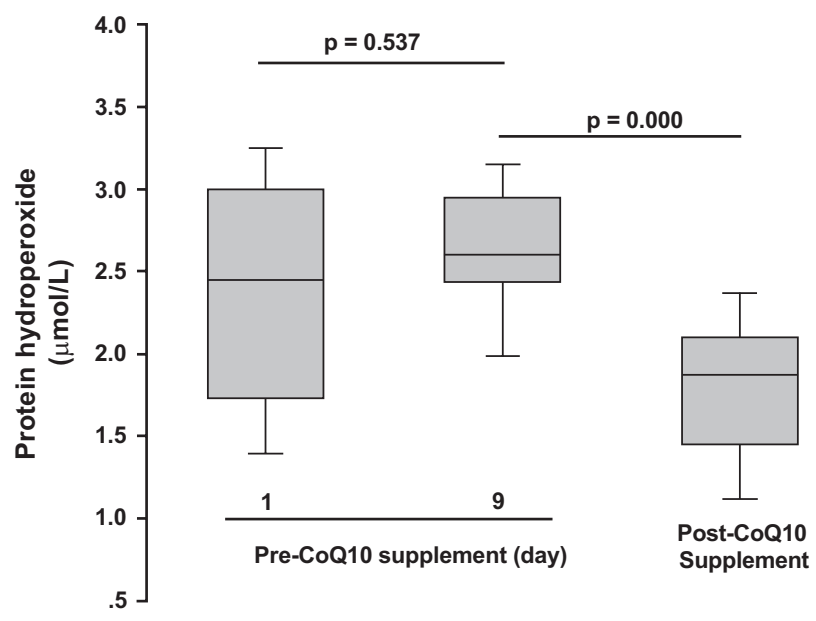

Fig. (3). Plasma $\mathrm{PrOOH}(\mu \mathrm{mol} / \mathrm{L})$ at days 1 and 9 of pre-CoQ10 supplementation and post-CoQ10 supplementation, at $300 \mathrm{mg}$ daily for 12 days in the 16 young swimmers. PrOOH was assayed with a FOX reagent. Each box plot represents the mean and standard deviation (SD). Repeated measurement in the general linear model and Bonferroni (Post Hoc) was used for statistical analysis with a $\mathrm{p} \leq 0.05$ level.

\section{DISCUSSION}

The present investigation included 16 swimmers who are being trained as future national swimmers representing Thailand. They have been swimming each week for a minimum of one year prior to the start of the study. In an attempt to control for confounding factors, all subjects were ordered to consistency maintain dietary intake and perform regular exercise training by swimming 5 kilometers every day, in addition to performing weight training each Friday. A limitation of our work is the lack of a control group. This should be considered in future studies.

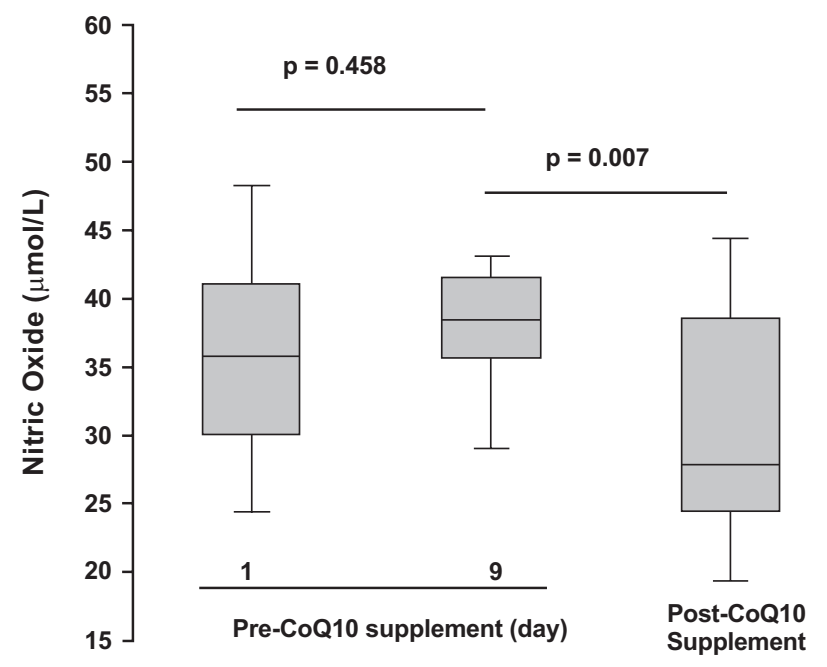

Fig. (4). GSH in erythrocyte $(\mu \mathrm{mol} / \mathrm{g} \mathrm{Hb})$ at days 1 and 9 of preCoQ10 supplementation and post-CoQ10 supplementation, at 300 $\mathrm{mg}$ daily for 12 days in the 16 young swimmers. GSH was assayed with the DTNB method. Each box plot represents the mean and standard deviation (SD). Repeated measurement in the general linear model and Bonferroni (Post Hoc) was used for statistical analysis with a $\mathrm{p} \leq 0.05$ level.

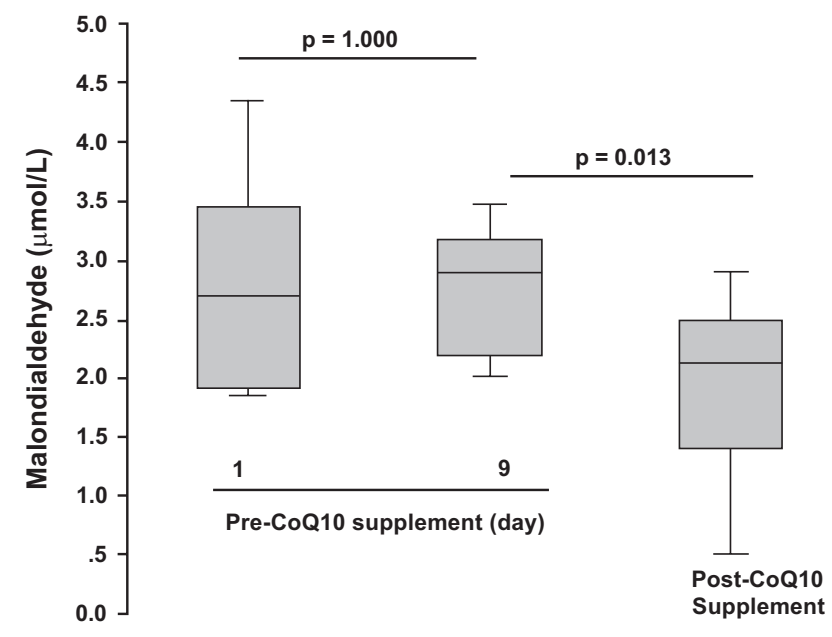

Fig. (5). Plasma TAC (mmol Trolox/L) at days 1 and 9 of preCoQ10 supplementation and post-CoQ10 supplementation, at 300 $\mathrm{mg}$ daily for 12 days in the 16 young swimmers. Plasma TAC was assayed with the ABTS cation radical decolorization method. Each box plot represents the mean and standard deviation (SD). Repeated measurement in the general linear model and Bonferroni (Post Hoc) was used for statistical analysis with a $\mathrm{p} \leq 0.05$ level.

This study was the first to our knowledge to investigate the effects of CoQ10 supplementation on oxidative stress and physical performance in healthy young swimmers. Baseline parameters of all the swimmers before CoQ10 supplementation were constant (day 1 vs day 9), with insignificant change within the nine day control period. Baseline assessment of oxidative stress biomarkers noted relatively high values for $\mathrm{MDA}, \mathrm{NOx}, \mathrm{ProOOH}$, and low levels of TAC and GSH (Table 2), compared to other related literature. This is the same as previously reported for young human swimmers [2], and agrees with animal studies using 


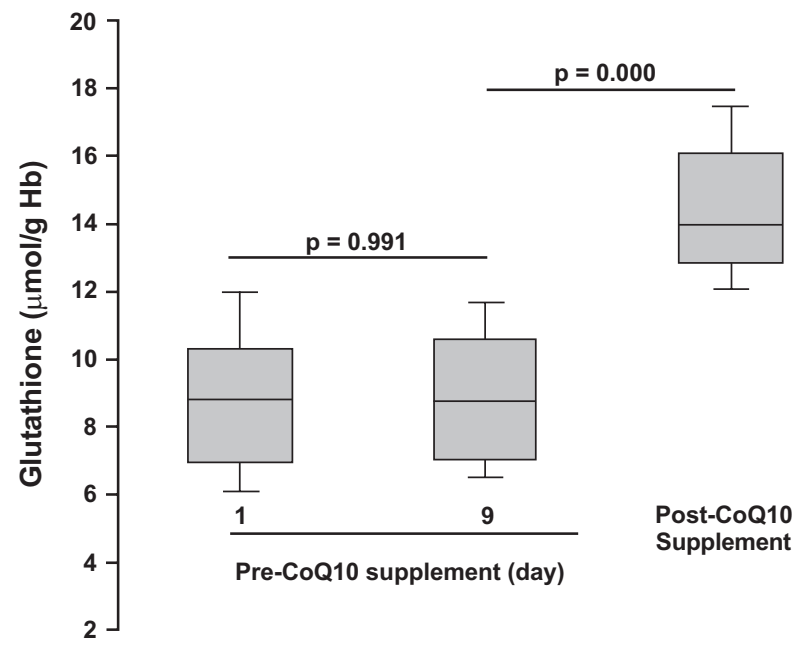

Fig. (6). Plasma CoQ10 $(\mu \mathrm{g} / \mathrm{ml})$ at days 1 and 9 of pre-CoQ10 supplementation and post-CoQ10 supplementation, at $300 \mathrm{mg}$ daily for 12 days in the 16 young swimmers. CoQ10 was assayed with a HPLC-UV. Each box plot represents the mean and standard deviation (SD). Repeated measurement in the general linear model and Bonferroni (Post Hoc) was used for statistical analysis with a $\mathrm{p} \leq 0.05$ level.

rodents exposed to repeated swimming, in which increased lipid peroxidation in the liver, kidneys, adrenal gland, and brain has been noted [3]. Moreover, swimming until exhaustion in rats has been reported to increased lipid peroxidation [21]. However, in opposition to our findings of elevated baseline values for oxidative stress biomarkers, young swimmers participating in four-weeks of regular swimming exercise have been noted not to present with any significant increase in lipid peroxidation [22].
NOx is generated continuously by skeletal muscle, a production that is increased by contractions [23]. Skeletal muscle normally expresses the neuronal (type I or nNOS) and endothelial (type III or eNOS) isoforms of NO synthase (NOS). The nNOS is strongly expressed in fast-twitch muscle fibers and localized to the muscle sarcolemma, where it is associated with the dystrophin-glycoprotein complex. It appears to be the prime source of the NOx released from skeletal muscle [24]. Rat models showed that strenuous swimming exercise for 3,6 , and 12 months increased plasma NOx significantly [25]. Moreover, swimming session at 75$88 \%$ of the maximal capacity induced mitochondrial superoxide dismutase (MnSOD) expression, and significant nitric oxide and iNOS gene expression, with $\mathrm{H}_{2} \mathrm{O}_{2}$ being released from lymphocytes more in female than male rats [26]. The high level of nitric oxide in cardiac muscle was a reversible regulation of respiration in cardiac tissue in situations of hypoxia and reoxygenation [27]. Zhang et al. (2007) [28] showed that in rats exercised in a 10 week swimming program, exercise increased myocardial NOx production, eNOS protein levels, and sensitivity to insulinstimulated phosphorylation of eNOS. It also mediated through the Akt signaling pathway to result in enhanced myocardial contractility. This study found a high level of plasma NOx, that was a physiological mediator of vascular tone to vasodilatation, and it inhibited platelet aggregation and leukocyte adhesion [29]. Thus, this is a protective mechanism that increases blood flow in the vital organs of the swimmer's body.

Glutathione $(\mathrm{GSH})$ is an endogenous antioxidant that controls free radical formation. The general mechanism of GSH is able to scavenge either free or non-radicals directly by glutathione peroxidase (GPX), which is shown in reaction

Table 2. Oxidative Stress Parameters; Nitric Oxide (NOx), Malondialdehyde (MDA), Protein Hydroperoxide (PrOOH), Glutathione (GSH), Total Antioxidant Capacity (TAC), and CoQ10 between Pre- and Post-CoQ10 Supplementation in the 16 Young Swimmers

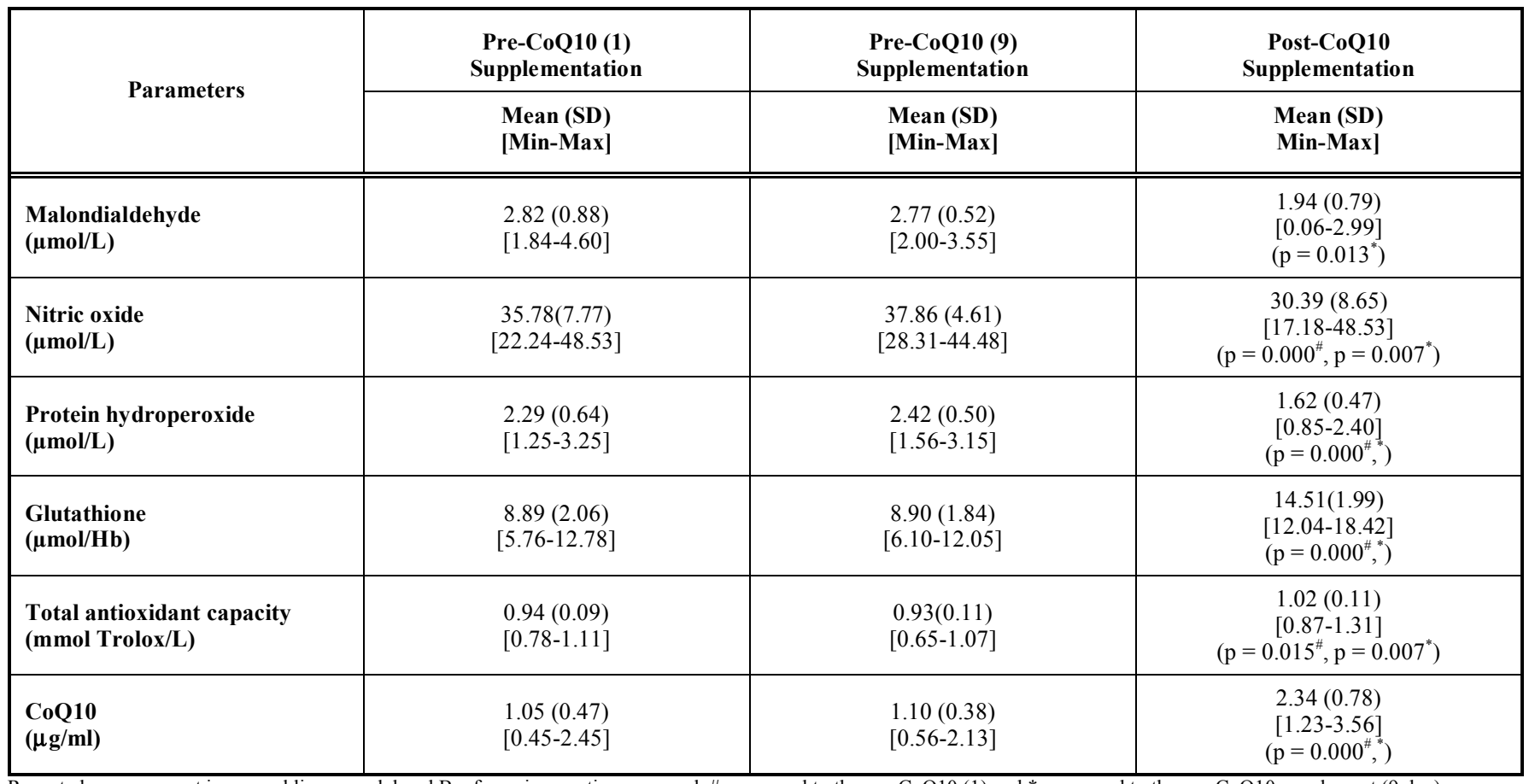

Repeated measurement in general linear model and Bonferroni correction was used. \# compared to the pre-CoQ10 (1) and * compared to the pre-CoQ10 supplement ( 9 day). 
Table 3. Physical Performance; Time to Exhaustion and the Fastest Swimming Times between Pre- and Post-CoQ10 Supplementation in the 16 Young Swimmers

\begin{tabular}{|c|c|c|c|}
\hline Physical Performance & $\begin{array}{c}\text { Pre-CoQ10 (1) } \\
\text { Supplementation }\end{array}$ & $\begin{array}{c}\text { Pre-CoQ10 (9) } \\
\text { Supplementation }\end{array}$ & $\begin{array}{c}\text { Post-CoQ10 } \\
\text { Supplementation }\end{array}$ \\
\hline Parameters & $\begin{array}{l}\text { Mean (SD) } \\
{[\text { Min-Max] }}\end{array}$ & $\begin{array}{l}\text { Mean (SD) } \\
\text { [Min-Max] }\end{array}$ & $\begin{array}{l}\text { Mean (SD) } \\
\text { [Min-Max] }\end{array}$ \\
\hline Time to exhaustion (min) & $\begin{array}{c}18.70(4.21) \\
{[13.01-26.02]}\end{array}$ & $\begin{array}{c}20.14(4.47) \\
{[13.28-29.04]}\end{array}$ & $\begin{array}{c}22.92(4.89) \\
{[16.12-31.04]} \\
\left(\mathrm{p}=0.000^{\#}, 0.009^{*}\right)\end{array}$ \\
\hline $\begin{array}{l}\text { Swimming time (second) } \\
\text { within } 100 \text { meters } \\
\text { within } 800 \text { meters }\end{array}$ & $\begin{array}{c}65.15(3.41) \\
{[58.59-70.32]} \\
\\
612.98(32.92) \\
{[560.44-683.13]}\end{array}$ & $\begin{array}{c}66.08(4.06) \\
{[58.50-72.02]} \\
607.12(35.10) \\
{[556.83-685.85]}\end{array}$ & $\begin{array}{c}66.71(4.27) \\
{[58.58-73.14]} \\
\left(\mathrm{p}=0.003^{\#}, 0.402^{*}\right) \\
609.01(32.57) \\
{[573.21-673.76]}\end{array}$ \\
\hline
\end{tabular}

Repeated measurement in general linear model and Bonferroni correction was used. \# compared to the pre-CoQ10 (1) supplementation and *compared to the pre-CoQ10 supplement (9 day).

1. Moreover, GSH reduces the organic hydroperoxide $(\mathrm{ROOH})$ to $\mathrm{H}_{2} \mathrm{O}$ as well as nitric oxide (NO) in reaction 2 and 3 below [30, 31].

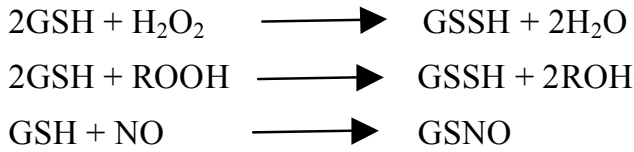

During the control period, the level of GSH was quite low, possibly due to the high threshold of oxidative stress from prolonged swimming. Previous work has noted that swimming until exhaustion in rats, increasesed lipid peroxidation and decreases GSH/GSSG ratio [32].

The CoQ10 supplement in soft gel form was provided in this study at a dosage of $300 \mathrm{mg}$ daily for 12 days. Previous reports have shown that the bioavailability of CoQ10, with a soft gel formulation in human plasma, can reach maximal concentration at 26.5 or $25.8 \mathrm{~h}$ following supplementation [33]. Thus, daily CoQ10 supplementation could provide maximal concentration in human plasma during experiments. Therefore, CoQ10 supplementation at $300 \mathrm{mg}$ daily for 12 days was noted to increase plasma CoQ10 levels approximately 2-fold compared to before supplementation (Table 2).

Previous reports suggest that CoQ10 in the ubiquinone form is essential for generating energy within mitochondria and providing antioxidant defense similar to the other fatsoluble antioxidants, such as vitamin E. This appears to be due to the scavenging of free radicals and prevention of oxidation of lipids and other molecules [34]. The concentration of Ubiquinol Q10 (UQ10) in human plasma varied between 0.4 and $1.0 \mu \mathrm{mol} / \mathrm{L}$ in a reduced form of about $80 \%$ [35] or $0.47 \pm 0.18 \mu \mathrm{g} / \mathrm{ml}$, with a range of $0.26-$ $1.03 \mu \mathrm{g} / \mathrm{ml}$ in 31 healthy subjects aged 18 to 56 years [36]. In the present study, CoQ10 could be detected in amounts close to those in a previous study of young swimmers (1.05 \pm 0.47 and $1.10 \pm 0.38 \mu \mathrm{g} / \mathrm{ml}$ in pre-supplement periods and $2.34 \pm 0.78 \mu \mathrm{g} / \mathrm{ml}$ after supplementation). Previous study showed that CoQ10 or Ubiquinol inhibited the lipid peroxidation and protein oxidation of the cell membrane, as in lipoprotein within circulation [37].
In a 1997 study in Finland, the effects of CoQ10 supplements at $90 \mathrm{mg}$ daily were studied in a double-blind cross-over study of 25 cross-country skiers. The results showed that all subjects significantly improved indexes of physical performance [38]. In opposition to these findings, a short-term (2 months) oral dose of CoQ10 at $150 \mathrm{mg} /$ day in middle-aged men increased CoQ10 circulation level in blood. It did not improve aerobic capacity [39].

In terms of antioxidant action, CoQ10 supplementation combined with antioxidants in soccer players during matches showed potential antioxidant activity by increased ascorbic acid and CoQ10 in plasma [40]. Twelve days of CoQ10 supplementation helped to reduce blood levels of lipid peroxidation products after exposure to free radicalproducing chemicals [41]. It is important to note that CoQ10 helps to protect LDL from oxidation, thereby reducing the risk of cascading events that may lead to conditions of atherogenesis [42].

The present study shows that CoQ10 supplementation at $300 \mathrm{mg}$ daily improves physical performance assessed via treadmill time to exhaustion, as well as the 100 meter swim. These findings support prior work, as discussed above, as well as work involving healthy subjects in which CoQ10 supplementation at $300 \mathrm{mg}$ daily, but not $100 \mathrm{mg}$ daily, to reduce fatigue and enhance physical performance [43]. Clearly, dosing is an important concern when considering CoQ10 supplementation. Although, CoQ10 is located within the inner mitochondrial membrane, is the cofactor of three mitochondrial enzymes (complex I, II and III), and plays an essential role in production of adenosine triphosphate (ATP) during exercise [44]. The present study noted significant changes in maximal swimming at 100 meters (approximately 66 second), as well as treadmill time to exhaustion which was increased significantly (approximately $22 \mathrm{~min}$ or 130 second). However, we failed to note any improvement in 800 meter swimming Swimming within 100 meters may be not use a significant amount of energy generated via aerobic pathways, but rather rely primarily on anaerobic glycolysis and ATP from creatine phosphate [45]. However, maximal time of running on the treadmill (approximately $20 \mathrm{~min}$ ) could have been largely impacted by CoQ10 functioning within the mitochondria via aerobic synthesis of ATP. A 
limitation of our work is the lack of CoQ10 measurement within skeletal muscle. However, previous work in healthy men who supplemented CoQ10 at $150 \mathrm{mg}$ daily for four weeks, as opposed to $300 \mathrm{mg}$ daily as in the present study, noted a nonsignificant change [46]. It is possible that a higher dosage (e.g., $300 \mathrm{mg}$ as used in the present study) may allow for increased muscle concentration; however this is presently unknown. Thus, knowledge of muscle uptake of CoQ10 within the mitochondria in muscle tissue needs further investigation.

From the present findings we can conclude that a short period of CoQ10 supplementation at a dosage equal to 300 mg per day decreases oxidative stress and enhances exercise performance (treadmill time and short swim sprint). Our data are in reference to young swimmers. Future work using larger samples, possibly of different sporting backgrounds, with the inclusion of a placebo group and a double blind research design are needed to extend these findings.

\section{ACKNOWLEDGEMENTS}

This project was supported by the Cerebos Award (Brand, co.th) in 2008. We especially thank the swimming coaches and all of the young swimmers' parents for their cooperation and assistance in controlling the food and CoQ10 supplementation during the entire study period.

\section{REFERENCES}

[1] Sokolovas G. High training and dry land training demands are not related to improvements in swimming performace. Demographic information. In: The Olympic Trials Project. Chapter 1. Colorado Springs, CO: United States Swimming. 2000. Available at: www.usa-swimming.org/programs/templated.pl?opt=news\&pubid= 941

[2] Gougoura S, Nilolaidis MG, Kostaropoulos IA, et al. Increased oxidative stress indices in the blood of child swimmers. Eur J Appl Physiol 2007; 100: 235-9.

[3] Nayanatara AK, Nagaraja HS, Anupama BK. The effect of repeated swimming stress on organ weights and lipid peroxidation in rats. Thai J Physiol Sci 2005; 18: 3-9.

[4] Hara M, Abe M, Suzuki T, Reiter RJ. Tissue changes in glutathione metabolism and lipid peroxidase induced by swimming are partially prevented by melatonin. Pharmacol Toxicol 1996; 78: 308-12.

[5] Beat K, Patrizia K, Rene K. Nutritional practices of extreme endurance swimmers the marathon-swim in the lake of Zurich 2006. Pak J Nutr 2007; 2: 188-93.

[6] Niklowitz P, Sonnenschein A, Janetzky B, Andler W, Menke T. Enrichment of coenzyme Q10 in plasma and blood cells: defense against oxidative damage. Int J Biol Sci 2007; 3: 257-62.

[7] Ernster L, Dallner G. Biochemical, physiology and medical aspects of ubiquinone function. Biochim Biophys Acta 1995; 1271: 28-41.

[8] Ylikoski T, Piirainen J, Hanninen O, Penttinen J. The effect of coenzyme Q10 on the exercise performance of cross-country skiers. Mol Aspects Med 1997; 18(Suppl): S283-90.

[9] Cooke M, Iosia M, Buford T, et al. Effects of acute and 14-day coenzyme Q10 supplementation on exercise performance in both trained and untrained individuals. J Int Soc Sport Nutr 2008; 5: 8.

[10] Miller MR, Crapo R, Hankinson J, et al. General considerations for lung function testing. Eur Respir J 2005; 26: 153-61.

[11] No Author Listed. Standarization of spiromter 1994, Update. American Thoracic Society. Am J Respir Crit Care Med 1995; 152: 1107-36.

[12] Griess reagent system; Instructions for use of product G2930. Technical bulletin. Promega. Printed in USA. Revised 6/05. Part\# TB229. Avalible at; www.promega.com

[13] Chirico S. High-performance liquid chromatography-based thiobarbituric acid tests. Methods Enzymol 1994; 233: 314-8.

[14] Leelarungrayub N, Chanarat N, Rattanapanone V. Potential activity of Thai shallot (Allium ascalonicum L.) extract on the prevention of hemolysis and glutathione depletion in human erythrocyte from oxidative stress. Chiang Mai Univ J 2004; 3: 225-34.

[15] Gay C, Gebicki JM. Measurement of protein and lipid hydroperoxides in biological systems by the ferric-xylenol orange method. Anal Biochem 2003; 315: 29-35.

[16] Leelarungrayub $\mathrm{N}$, Rattanapanone V, Borisuthibandit $\mathrm{T}$, Kongtawelert P, Banjerdopongchai R, Chanarat N. Correlation between malondialdedhye (MDA), hyaluronan (HA), and alphatocopherol (VitE) in tracheal aspirated fluid (TAF) and oxygenation index $\left(\mathrm{PaO}_{2} / \mathrm{FiO}_{2}\right)$ in pediatric patients with chronic lung disease. Bull Chiang Mai Assoc Med Sci 2003; 36: 24-34.

[17] Re R, Pellegrini N, Proteggente A, Pannala A, Yand M, RiceEvans C. Antioxidant activity applying an improved ABTS radical cation decolorization assay. Free Radic Bio Med 1999; 26: 1231-7.

[18] Graves S, Sikorska M, Borowy-Borowski H, Ho RH, Woodhouse C. Analysis of coenzyme Q10 content in human plasma and other biological samples. In: Armstrong D, Ed. Methods in molecular biology: free radical and antioxidant protocols. New Jersey: Humana Press 1998; Vol. 108: pp. 353-65.

[19] ACSM's guidelines for exercise testing and prescription. Philadelphia: Lippincott Williams\&Wilkins 2000.

[20] ATS-ERS Pulmonary function standards task force. Standards for pulmonary function testing and interpretation strategies. Eur Respir J 2005; 26:153-161, 319-338, 511-522, 720-735, 948-68.

[21] Veskoukis AS, Nikolaidis MG, Kyparos A, et al. Effects of xanthine oxidase inhibition on oxidative stress and swimming performance in rats. Appl Physiol Nutr Metab 2008; 6: 1140-54.

[22] Gonenc, S, Acikgoz O, Semin I, Ozgonul H. The effect of moderate swimming exercise on antioxidant enzymes and lipid peroxidation levels in children. Indian J Physiol Pharmacol 2000; 3: 340-4.

[23] Balon TW, Nadler JL. Nitric oxide release is present from incubated skeletal muscle preparations. J Appl Physiol 1994; 77: 2519-21.

[24] Jackson MJ. Reactive oxygen species and redox regulation of skeletal muscle adaptations to exercise. Philos Trans R Soc Lond B Biol Sci 2005; 360: 2285-91.

[25] Xiao DS, Qian ZM. Plasma nitric oxide and iron concentrations in exercise rats are negatively correlated. Mol Cell Biochem 2000; 208: 163-6.

[26] Sureda A, Ferrer MD, Tauler P, Tur JA, Pons A. Lymphocyte antioxidant response and $\mathrm{H} 2 \mathrm{O} 2$ production after a swimming session: gender differences. Free Radic Res 2008; 42: 312-9.

[27] Xie YW, Wolin MS. Role of nitric oxide and its interaction with superoxide in the suppression of cardiac muscle mitochondrial respiration; Involvement in response to hypoxia/reoxygenation. Circulation 1996; 94: 2580-6.

[28] Zhang QJ, Li QX, Zhang HF, et al. Swim training sensitizes myocardial response to insulin: role of Akt-dependent eNOS activation. Cardiovasc Res 2007; 75: 369-80.

[29] Wallis JP. Nitric oxide and blood: a review. Transfus Med 2005; 15: 1-11.

[30] Cohen G, Hochstein P. Glutathione peroxidase: the primary agent for the elimination of hydrogen peroxide in erythrocyte. Biochemistry 1963; 2: 1420-8.

[31] Powers SK, Sen CK. Physiology antioxidants and exercise training. In: Sen CK, Packer L, Hanninen O, Eds. Hand book of oxidants and antioxidant in exercise. Tokyo: Elsevier Science BV 2000; pp. 221-39.

[32] Veskoukis AS, Nikolaidis MG, Kyparos A, et al. Effects of xanthine oxidase inhibition on oxidative stress and swimming performance in rats. Appl Physiol Nutr Metab 2008; 6: 1140-54.

[33] Evans M, Baisley J, Barss S, Guthrie N. A randomized, doubleblind trial on the bioavaibility of two CoQ10 formulations. J Funct Food 2009; 1; 65-73.

[34] Kagan VE, Serbinova EA, Packer L. Antioxidant effects of ubiquinones in microsomes and mitochondria are mediated by tocopherol recycling. Biochem Biophys Res Commun 1990; 169: 851-7.

[35] Stocker R, Frei B. Oxidative stress: oxidants and antioxidants. In: Sies H, Ed. Sandiego: Academic Press 1991; pp. 213-43.

[36] Kaplan P, Sebestianova N, Turiakova J, Kucera I. Determination of Coenzyme Q in human plasma. Physiol Res 1996; 45: 39-45.

[37] Littarru GP, Tiano L. Bioenergetic and antioxidant properties of coenzyme Q10: recent developments. Mol Biotechnol 2007; 37: 31-7. 
[38] Ylikoski T, Piirainen J, Hanninen J, Penttinen J. The effect of coenzyme Q10 on the exercise performance of cross-country skiers. Mol Aspects Med 1997; 18: 283-90.

[39] Porter DA, Costill DL, Zachwieja JJ, et al. The effects of oral coenzyme Q10 on the exercise tolerance of middle-aged untrained men. Int J Sport Med 1995; 16: 421-7.

[40] Tauler P, Ferrer MD, Sureda A, et al. Supplementation with an antioxidant cocktail containing coenzyme Q prevents plasma oxidative damage induced by soccer. Eur J Appl Physiol 2008; 104: 777-85.

[41] Lönnrot K, Holm P, Lagerstedt A, Huhtala H, Alho H. The effects of lifelong ubiquinone Q10 supplementation on the Q9 and Q10 tissue concentrations and life span of male rats. Biochem Mol Biol Int 1998; 44: 727-37.
[42] Neuzil J, Witting PK, Stocker R. Alpha-tocopherol hydroquinone is an efficient multifunctional inhibitor of radical-initiated oxidation of low density lipoprotein lipids. Proc Natl Acad Sci USA 1997; 94: 7885-90.

[43] Mizuno K, Tanaka M, Nozaki S, et al. Anti-fatigue effects of coenzyme Q10 during physical fatigue. Nutrition 2008; 24: 293-9.

[44] Crane FL, Sun IL, Sun EE. The essential functions of coenzyme Q. Clin Investig 1993; 71: S55-S9.

[45] Robergs RA, Keteyian SJ. Metabolic adaptations to exercise Fundamentals of exercise physiology. $2^{\text {nd }}$ ed. Toronto: McGraw Hill 2003; pp. 110-39.

[46] Zhou S, Zhang Y, Davie AJ, et al. Muscle and plasma coenzyme Q10 concentration, aerobic power and exercise economy of health men in response to four weeks of supplementation. J Sports Med Phys Fitness 2005; 45: 337-46.

(C) Leelarungrayub et al.; Licensee Bentham Open.

This is an open access article licensed under the terms of the Creative Commons Attribution Non-Commercial License (http://creativecommons.org/licenses/by-nc/3.0/) which permits unrestricted, non-commercial use, distribution and reproduction in any medium, provided the work is properly cited. 